\title{
Estudo das propriedades físicas e mecânicas com a composição química de argilas vermelhas do Estado da Bahia
}

\author{
Study of the physical and mechanical \\ properties with the chemical composition \\ of red clays from the State of Bahia
}

Tereza Cristina de Farias Guimarães ${ }^{1}$, Arnaud Victor dos Santos ${ }^{1}$, Ariane da Cruz Thedoldi ${ }^{1}$, Danilo Carvalho de Lima ${ }^{1}$

\footnotetext{
${ }^{1}$ Laboratório de Ciência e Tecnologia de Materiais -LCTM / DCET I/Universidade do Estado da Bahia - UNEB, Avenida Silveira Martins, 255, CEP: 41195-001, Cabula, Salvador, Bahia, Brasil.

E-mail: tcfg@uneb.br, avsantos@uneb.br
}

\section{RESUMO}

Este trabalho verificou a dependência das propriedades físicas e mecânicas com a composição química de várias argilas vermelhas do Estado da Bahia. Preservou-se a granulometria dos materiais em peneiras de até 30 mesh. Para caracterização físico-química e mecânica foram realizados os ensaios: limite de plasticidade, limite de liquidez, índice de plasticidade, coloração subsequente à queima em 900/1000/1100 ${ }^{\circ} \mathrm{C}$, retração linear, módulo de tensão de ruptura, determinação de água de absorção, distribuição granulométrica, umidade natural e perda de massa ao fogo (modo flamejante). Em paralelo empregou-se a técnica de Espectrometria de Emissão Óptica com Plasma Indutivamente Acoplado - ICP - OES, Modelo Perkin Elmer Optima 8300 para determinação da composição química das argilas. Os resultados evidenciaram a dependência das propriedades com a composição química das argilas de forma sinergética e conciliativa.

Palavras-chave: Argilas Vermelhas; Composição; Propriedades Físico-Químicas; Caracterização.

\section{ABSTRACT}

This work verified the dependence of the physical and mechanical properties with the chemical composition of several red clays in the State of Bahia. The granulometry of the materials was preserved in screens up to 30 mesh. For physical-chemical and mechanical characterization, the following tests were performed: plasticity limit, liquidity limit, staining after burning at $900 / 1000 / 1100{ }^{\circ} \mathrm{C}$, linear retraction, rupture stress module, determination of absorption water, particle size distribution, natural moisture, and loss of mass to fire (flaming mode). In parallel, the technique of Optical Emission Spectrometry with Inductively Coupled Plasma - ICP - OES, Model Perkin Elmer Optima 8300 was used to determine the chemical composition of the clays. The results showed the dependence of properties on the chemical composition of clays in a synergistic and conciliatory way.

Keywords: Red Clays; Composition; Physical-Chemical Properties; Description.

\section{INTRODUÇÃO}

Um dos setores industriais que mais tem contribuído com a alteração da morfologia terrestre é a indústria de cerâmica vermelha, sendo considerado como o mais antigo da civilização. Sua história se intersecta com a própria história da humanidade atuando como um dos mais importantes da economia mundial [1]. Segundo a ANFACER (2012), em 2011 o Brasil fechou o ano com o melhor resultado da história, onde, a produtividade no setor cerâmico apresentou crescimento de $12,5 \%$, alcançando um volume de 844,32 milhões de m2 e 
deixando o país na posição de segundo maior produtor mundial, ficando à frente dos polos produtivos da Europa, Itália e Espanha [2]. O desenvolvimento do setor industrial de cerâmica vermelha acarretou nos últimos anos, um aumento representativo de micro e pequenas empresas por todo o país, com grande destaque para as regiões semiáridas, pois nestas localidades há maior disponibilidade de matéria-prima de baixo custo, o que favorece o crescimento espacial e econômico do setor [3]. Na Bahia existem polos de produção do segmento cerâmico tradicionais situados nas regiões do Recôncavo Baiano e no Extremo Sul da Bahia onde o CBPM (Companhia Bahia de Pesquisas Minerais) detém alguns direitos minerais desses depósitos argilosos [4].

Geralmente, as argilas são materiais muito heterogêneos, cujas características dependem da sua formação geológica e da localização da extração [5]. O conhecimento da faixa mineralógica das argilas é imprescindível para sua adequada inserção em diversos processos industriais. A qualidade dos produtos cerâmicos está ligada principalmente às propriedades químicas, tecnológicas e mineralógicas das argilas empregadas, tais como: granulometria, plasticidade, composição, dentre outras [6]. Sendo assim, notabilizase uma imperativa necessidade da realização de estudos que objetivem a caracterização das argilas com o intuito de extrair ao máximo seu verdadeiro potencial tecnológico.

A cerâmica vermelha precisa da argila para fabricação de blocos cerâmicos, telhas, tubos cerâmicos etc. Argila, matéria-prima para produção da cerâmica vermelha, é um material natural, terroso, composto por partículas finas, que geralmente adquire plasticidade quando em contato com água, e resistência mecânica após tratamento térmico [7].

As chamadas argilas de queima vermelha ou argilas comuns apresentam maior destaque entre as substâncias minerais, por causa do volume de produção e do maior consumo, sendo especialmente utilizadas na produção de cerâmica vermelha e de revestimento. Este setor da indústria representa 0,59\% do PIB do Brasil, e 2,5\% do PIB industrial brasileiro [8].

Essas argilas comuns (common clay), abrangem uma grande variedade de substâncias minerais de natureza argilosa. Compreendem, basicamente, sedimentos pelíticos consolidados e inconsolidados, como argilas aluvionares quaternárias, argilitos, siltitos, folhelhos e ritmitos, que queimam em cores avermelhadas, a temperaturas variáveis entre 800 e $1250^{\circ} \mathrm{C}$ [9].

São sistemas complexos constituídos por substâncias orgânicas e inorgânicas que variam de acordo com a jazida e influenciam no processo de fabricação e nas características dos produtos cerâmicos. As argilas que possuem compostos higroscópicos e menor presença de silício como a montmorilonita, são mais plásticas, pois retêm mais água durante a mistura e apresentam uma maior retração durante a secagem. Algumas das substâncias comumente encontradas nas argilas são $\mathrm{SiO}_{2}, \mathrm{Al}_{2} \mathrm{O}_{3}, \mathrm{Fe}_{3} \mathrm{O}_{2}, \mathrm{CaO}, \mathrm{MgO}, \mathrm{Na}_{2} \mathrm{O}$ e $\mathrm{K}_{2} \mathrm{O}$. Para corrigir as variações que a composição destas matérias-primas está sujeita deve-se realizar misturas de diferentes argilas, garantindo a homogeneidade para podermos fabricar produtos com características semelhantes [10]. Então, as argilas que apresentam limites de plasticidade dentro da faixa indicada para cerâmica vermelha são constituídas basicamente por caulinita, quartzo, mica e feldspatos, com algumas amostras apresentando goetita e hidróxido sílico-aluminoso [5].

As argilas vermelhas podem ser também classificadas conforme a maior ou menor quantidade de coloides: as "fortes" ou "gordas" são muito plásticas, devido à alumina deformam-se muito no processo de cozimento; as "fracas" que possuem excesso de sílica (mais arenosas) são mais porosas e frágeis ou "magras" [11]. Em 2019, RACANELLI et al.[12] concluíram com ensaios de caracterização das argilas in natura revelaram que elas são constituídas, sobretudo por caulinita, quartzo e mica muscovita. A Argila Forte (AFO), ou seja, massa sem adição de outro tipo de massa argilosa apresenta como fases cristalinas predominantes a caulinita, quartzo, mica muscovita e anatásio. Analisando a Argila Fraca (AFR) também sem nenhum outro tipo de massa adicionada para sua formulação, apresentou fases cristalinas semelhantes ás da Argila Forte. Logo, a presença de caulinita revelou que as argilas usadas são cauliníticas e que podem apresentar boa plasticidade.

Diante dos resultados, percebeu-se que as duas argilas da região apresentam boas características para fabricação tanto de telhas quanto de blocos de vedação. No entanto, para informações mais precisas quanto a eficiência da resistência desses materiais que são comercializados; é necessário que se faça analises referentes à testes mecânicos baseados nas normas regulamentadoras para fabricação de blocos de vedação e telhas especificamente.

Assim, o presente trabalho trata como estudo a utilização destes dois tipos de matérias-primas para serem utilizados para fabricação tanto de bloco de vedação quanto de telhas dando ênfase as composições químicas. 
As caracterizações de argilas vermelhas coletadas em diversas cidades do Estado da Bahia, pelo grupo do Laboratório de Ciência e Tecnologia de Materiais, LCTM/DCET I da UNEB, assim como as argilas vermelhas ou "queima escura" selecionadas pelo CBPM, tiveram como finalidade contribuir na produção de blocos e telhas bem como para formulações fritas e esmalte utilizadas nas aplicações de segunda e terceira queima das cerâmicas industriais e artesanais do Estado da Bahia.

\section{MATERIAIS E MÉTODOS}

Em princípio, nesse estudo foram analisadas argilas utilizadas industrialmente para a produção de blocos cerâmicos nas cidades de Simões Filho, Dias D’Ávila, Nazaré, Camaçari e Alagoinhas situadas no Estado da Bahia. Para uma amostragem significativa, todas foram retiradas de diversos locais, misturadas, secas, peneiradas com malhas de 0,297 mm segundo norma da ABNT, e caracterizadas por meio da granulometria (determinação da distribuição de tamanho de partículas), seguindo as diretrizes da NBR 7181 (ABNT, 1984) [13], limites de Atterberg - liquidez e plasticidade, conforme normalização vigente [14].

Para a quantificação da composição química por via úmida, as amostras foram preparadas a partir da Digestão Ácida Assistida por Micro-ondas (modelo Milestone Ethos 1) e, posteriormente, utilizando-se no Espectrômetro de Emissão Ótica por Plasma Indutivamente Acoplado (ICP-OES) da Perkin Elmer modelo Optma8300. Para caracterização físico-química, foram preparados previamente corpos de prova com dimensões aproximadas de $2 \times 3 \times 2 \mathrm{~cm}$, por extrusão à vácuo. Em seguida, foram secos em estufa a $110{ }^{\circ} \mathrm{C}$ (modelo FANEM), com posterior incineração em 900, 1000 e $1100{ }^{\circ} \mathrm{C}$, a $3,5{ }^{\circ} \mathrm{C} \mathrm{min}^{-1}$ e isoterma de 60 min para cada temperatura, empregando forno tipo câmara com aquecimento elétrico da marca Brasimet.

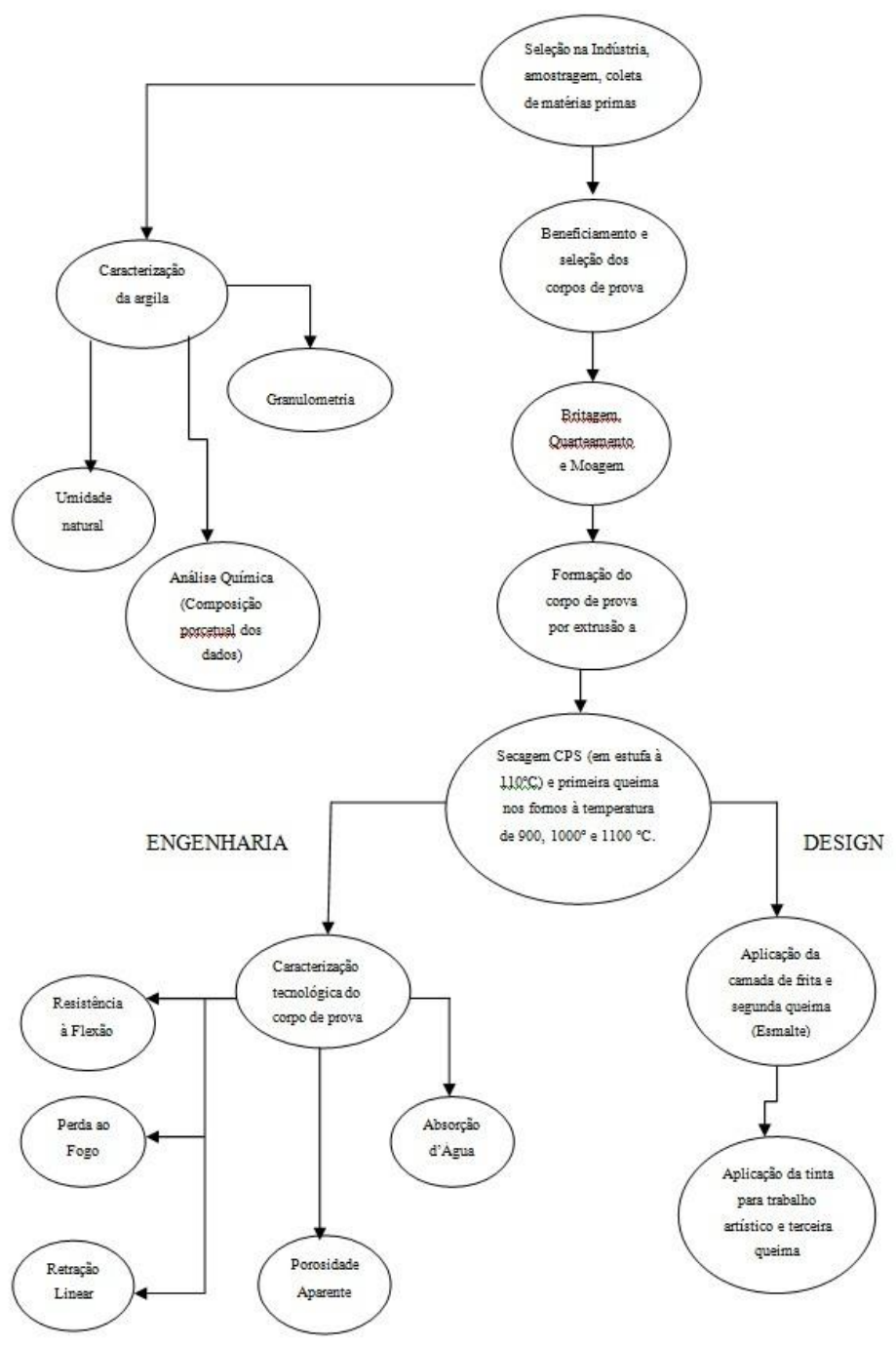

Figura 1: Processo industrial 
A Figura 1 ilustra esquematicamente todo processo desde a seleção na indústria, amostragem e coleta de matérias-primas até a caracterização tecnológica do corpo de prova destinada à Engenharia, e a aplicação da camada de frita e de tinta, segunda e terceira queima, respectivamente, direcionada à área de Design (Figura 2).

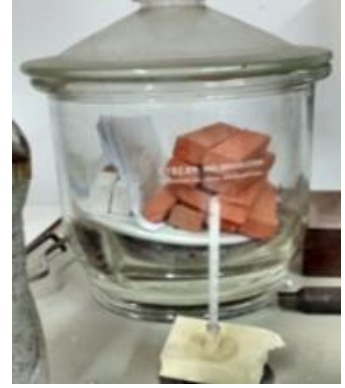

$1^{\mathrm{a}}$ queima

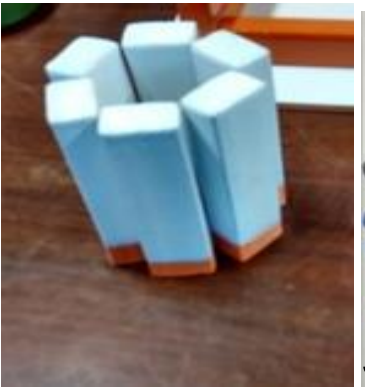

$2^{\mathrm{a}}$ queima

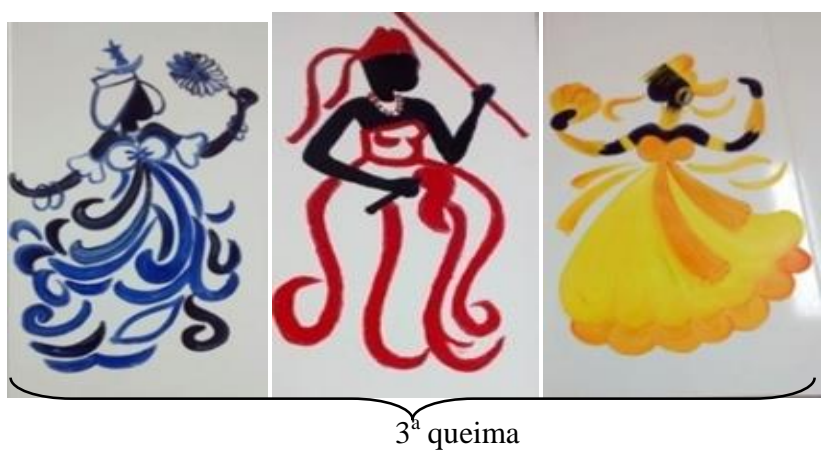

Figura 2: Corpos de prova após a primeira, segunda e terceira queima.

Os ensaios físicos e mecânicos das amostras foram realizados empregando um flexômetro da marca Gabbrielli, modelo CRAB-424, no qual foi determinado o módulo de ruptura à flexão (MRF) pelo método dos três apoios, mantendo a velocidade de aproximação do cutelo de $1,5 \mathrm{~mm} \cdot \mathrm{min}^{-1}$ e sua velocidade de teste de 2,5 mm. $\mathrm{min}^{-1}$. Para cada uma das temperaturas $\left(900,1000\right.$ e $1100{ }^{\circ} \mathrm{C}$ ) foram rompidos cinco corpos de prova da amostra seca em estufa antes da queima e mais cinco após a queima. A absorção de água, para os corpos de prova nas temperaturas de incineração, foi medida e calculada de acordo com a ASTM C373 [15] empregando um Banho MARIA STERILIFER, modelo BM 5DM.

Para obtenção das propriedades cerâmicas de retração linear de secagem (RLS) e retração linear de queima (RLQ), empregou-se um paquímetro manual para aferição dos comprimentos de secagem e queima. A medida de referência inicial foi de $10 \mathrm{~cm}$ para a RLS (comprimento inicial, Lo), marcado sob o corpo de prova logo após passagem pela extrusora, e o valor final (L: comprimento final) extraído após secagem na estufa. No caso da RLQ, o Lo advém do comprimento subsequente à estufa e o L calculado depois da queima nas temperaturas de incineração $\left(900,1000\right.$ e $\left.1100{ }^{\circ} \mathrm{C}\right)$.

\section{RESULTADOS}

As amostras apresentam largas distribuições granulométricas, obtendo-se partículas mais "finas" para as amostras de Nazaré e Dias D'Ávila e as mais "grosseiras" encontradas nas amostras da cidade de Simões Filho e Camaçari (Figura 3). 


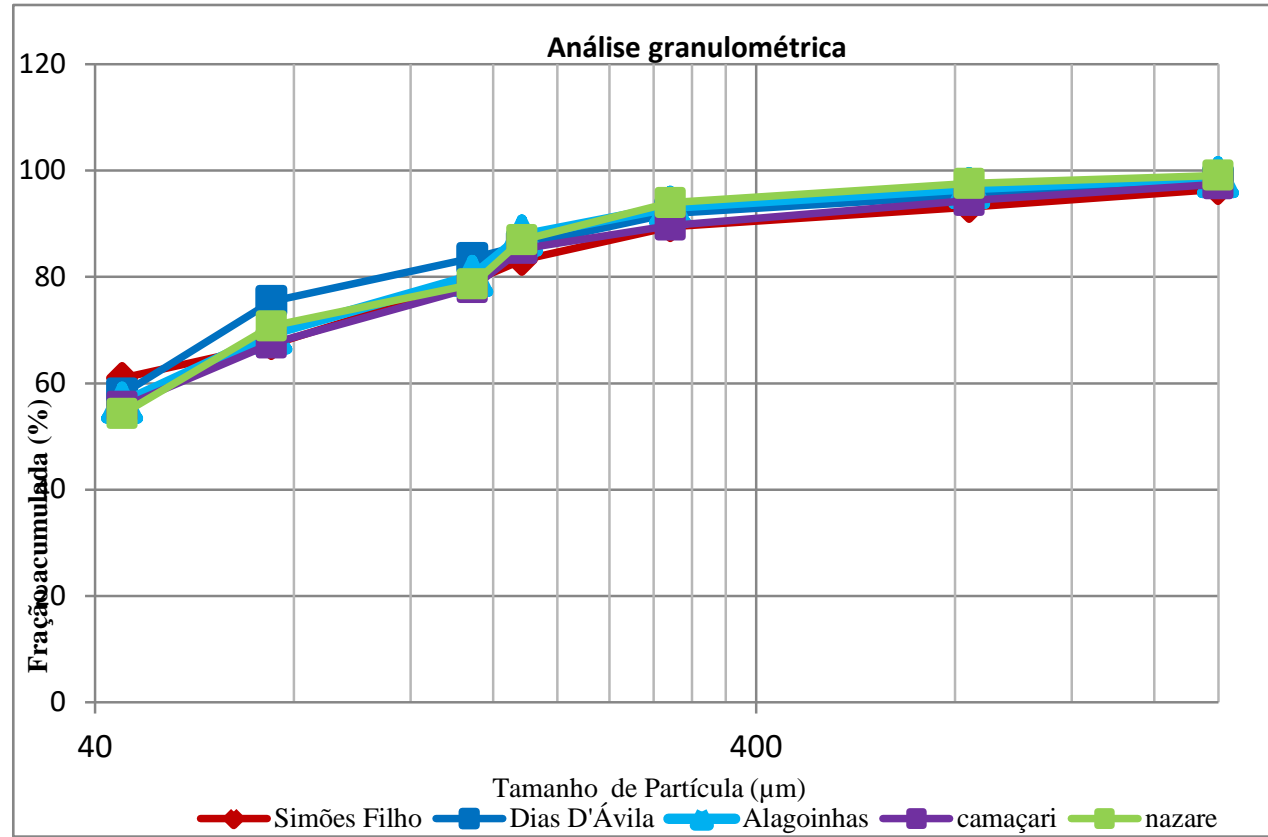

Figura 3 Análise granulométrica.

A amostra de Alagoinhas apresentou composição intermediária, em virtude possivelmente, de pertencerem a mesma bacia hidrográfica CBH Recôncavo Norte e Inhambupe. As amostras Camaçari e Simões Filho apresentam semelhança em suas granulometrias. A amostra Nazaré proveniente da bacia hidrográfica Paraguaçu destaca-se por uma distribuição granulométrica ligeiramente diferente das demais, principalmente na faixa silto-argilosa. A fração granulométrica com dimensão inferior a $2 \mu \mathrm{m}$ é considerada como sendo o teor argiloso da mistura [16].

Uma massa cerâmica por não poder ser constituída apenas de argila (em virtude de dificuldades que surgiriam no processamento), ela é formulada contendo materiais não plásticos, o que acarreta uma "mistura" de granulometrias, sendo a fração mais "fina" associada à argila e as demais ("mais grosseira") relacionadas aos materiais friáveis (silte e areia) [5].

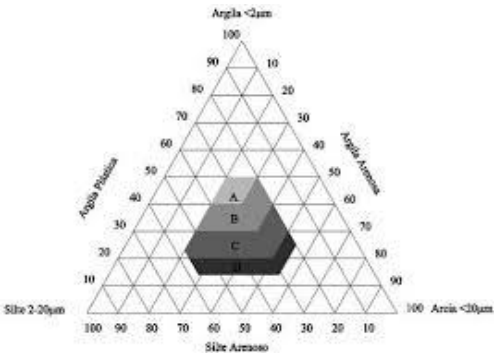

Figura 4: Diagrama de Winkler

Pelo diagrama de Winkler [18], dentre as cinco amostras analisadas nenhuma foi apropriada para fabricação de produtos de difícil conformação e que necessitam de uma massa com alta plasticidade (Região A). Por sua vez, as amostras Simões Filho e Alagoinhas (teor de argila plástica compreendido no intervalo de 30 a 38\%) podem ser indicadas para a produção de telhas (Região B). Finalmente, as amostras com o menor teor de argila plástica (intervalo entre 20 a 30\%) (Região C) da Figura 4, Nazaré, Dias d'Ávila e Camaçari possuem distribuições granulométricas ideais para fabricação de tijolos furados, - Através de pesquisas científicas é possível fornecer uma maior flexibilidade nas aplicações das argilas vermelhas do Estado da Bahia, redução de custos de produção e aumento no valor agregado do produto final; (Tabela 3-7).

O diagrama de Winkler auxilia no estudo da composição granulométrica ótima, sinalizando o porcentual de partículas finas, médias e grossas, obtendo as melhores propriedades para o produto acabado. Entretanto, trabalhos avaliando a viabilidade de utilização de argilas em cerâmica vermelha, indicaram argilas, cujas composições não se encaixavam na região do diagrama de Winkler, como adequadas para a produção de blocos cerâmicos [17]. 
A Tabela 1 apresenta os resultados do Limite de Liquidez, Limite de Plasticidade e Índice de Plasticidade das amostras coletadas nas cidades de Simões Filho, Dias D’Ávila, Alagoinhas, Camaçari e Nazaré.

Tabela 1: Limite de Liquidez, Limite de Plasticidade e Índice de Plasticidade.

\begin{tabular}{c|c|c|c}
\hline AMOSTRAS & LIMITE DE LIQUIDEZ (\%) & LIMITE DE PLASTICIDADE (\%) & ÍNDICE DE PLASTICIDADE (\%) \\
\hline Simões Filho & 54,2 & 30,3 & 23,9 \\
\hline Dias D'Ávila & 52,2 & 26.7 & 28,1 \\
\hline Alagoinhas & 53,4 & 33,2 & 20,2 \\
\hline Camaçari & 57,6 & 26,8 & 30,8 \\
\hline Nazaré & 48,5 & 27,5 & 23,3 \\
\hline
\end{tabular}

A amplitude do Limite de Liquidez (LL) abrangeu a faixa de 48,5 a 57,6\%, enquanto o Limite de Plasticidade (LP) situou-se entre 26,7 e 33,2\%. O menor valor registrado para o Índice de Plasticidade (IP) foi de $20,2 \%$ ao passo que o maior foi de $30,8 \%$ para a cidade de Camaçari. A diferença na plasticidade, possivelmente, é refletida por alguma variação mineralógica ou quantidade de matéria orgânica que vem a corroborar com MACEDO (2008) [5]. Observa-se que na Tabela 2 o maior teor de $\mathrm{Al}_{2} \mathrm{O}_{3}$ igual a 17,43\% foi para cidade de Camaçari, que pode te contribuído de certa forma para o aumento da Resistência Mecânica tendo em vista que torna a argila mais "forte" ou mais "gorda" (Figura 5). Mas observando a Figura 6, Nazaré e Alagoinhas apresentaram menores absorção de água (AA) e na Figura 7 maiores perdas ao fogo (PF) que possivelmente pode ser um indicativo da existência de materiais orgânicos que contribuem para o aumento da resistência mecânica como veremos no decorrer do trabalho.

Nas Tabelas de 2 a 7 observa-se que a presença de $\mathrm{Fe}_{2} \mathrm{O}_{3}$ as amostras variaram de $\geq 4,0$ a 7,26\% típico das argilas vermelhas, com exceção da argila comum, tipo formacional, encontrada no Extremo Sul da Bahia no município de Mascote com o teor de 12,50\%, dentro da faixa observada para argilas cauliníticas, e valores entre $4,26 \%$ e $11,12 \%$, estando de acordo com a faixa observada na literatura para argilas bentoníticas sulamericanas [19].

Na Tabela 2 a amostra de Nazaré contém 15,88\% de $\mathrm{Al}_{2} \mathrm{O}_{3}$, e seu somatório de elementos alcalinos foi de 5,59\%, a resistência à ruptura na flexão foi de $8,9 \mathrm{MPa}$, equivalente à de Alagoinhas correspondente a 8,9 MPa (Figura 5). Observa-se ainda uma menor resistência a ruptura na flexão para a amostra de Simões Filho de 4,8 $\mathrm{MPa}$, com menor quantidade de elementos alcalinos e menor porcentagens de $\mathrm{Al}_{2} \mathrm{O}_{3}$ do que a amostra de Camaçari, que apresentou 5,1 MPa e Dias d'Ávila com 5,3 MPa.

Tabela 2: Argila comum, tipo várzea, Recôncavo. Composição química porcentual (\%) [4].

\begin{tabular}{c|c|c|c|c|c|c|c}
\hline MUNICÍPIO & $\mathbf{S i O}_{2}$ & $\mathbf{A l}_{2} \mathbf{O}_{3}$ & $\mathrm{Fe}_{2} \mathbf{O}_{3}$ & $\mathbf{N a}_{2} \mathbf{O}$ & $\mathbf{K}_{\mathbf{2}} \mathbf{O}$ & $\mathbf{M g O}$ & $\mathbf{C a O}$ \\
\hline Dias D’Ávila & 65,95 & 16,46 & 7,26 & 0,11 & 2,33 & 1,61 & 0,11 \\
\hline Simões Filho & 63,16 & 16,41 & 6,98 & 0,05 & 1,10 & 0,52 & 0,16 \\
\hline Camaçari & 66,33 & 17,43 & $\geq 4$ & 0.11 & 1,23 & 0,49 & 0,08 \\
\hline Nazaré & 61,13 & 15,88 & 7,35 & 0,13 & 3,08 & 2,06 & 0,32 \\
\hline Alagoinhas & 70,08 & 18,64 & $\geq 4$ & 0,11 & 2,52 & 0,58 & 0,04
\end{tabular}




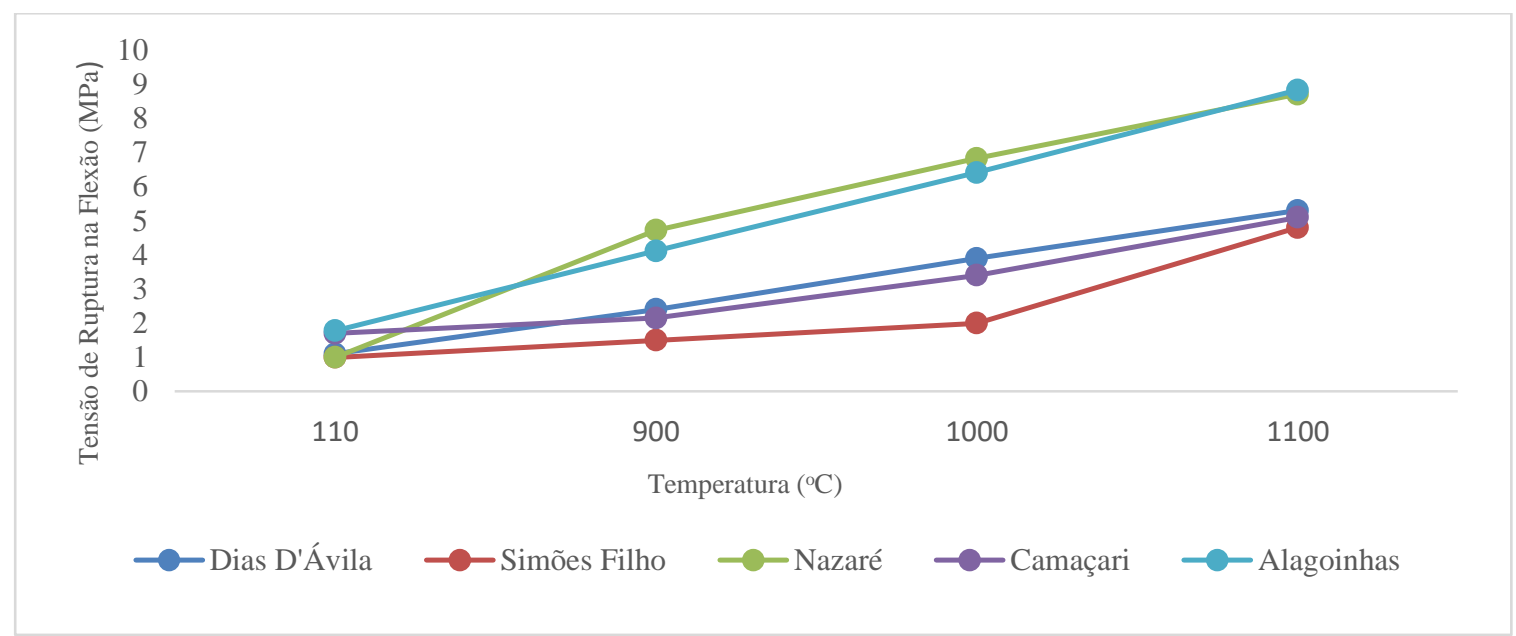

Figura 5: Tensão de ruptura na flexão (MPa) em função da temperatura.

Essas mesmas tendências são observadas nas demais Tabelas de 3 a 7 . A Figura 5 mostra o monitoramento da resistência à ruptura na flexão das amostras quando aquecidas em $110,900,1000$ e $1100^{\circ}$ C. Para a produção de blocos cerâmicos é indicado valores superiores a 5,0 MPa. Contudo, o grande campo de amostragem impõe certa heterogeneidade, mas outros fatores do processo podem ser otimizados, assim como alguma mistura de matérias-primas.

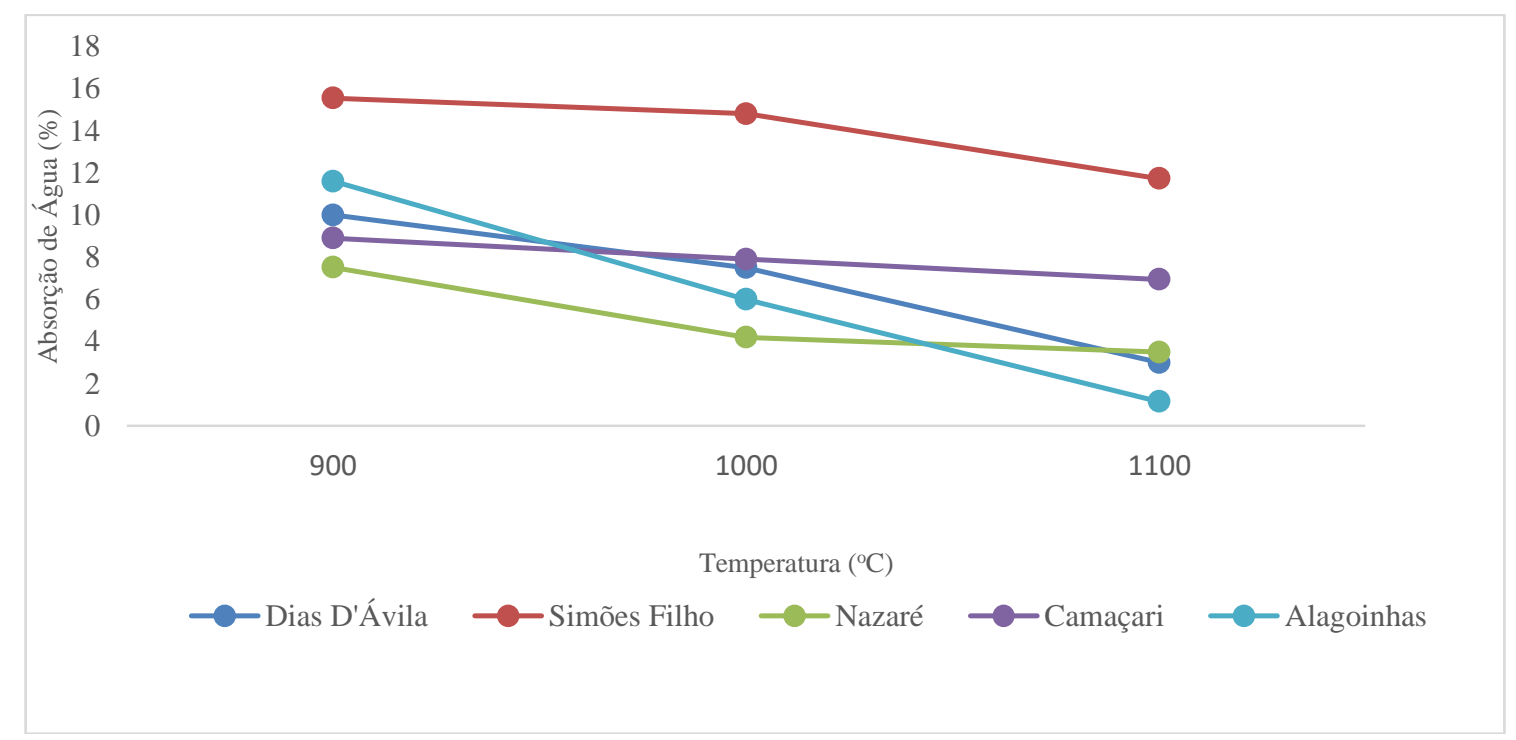

Figura 6: Absorção de água em função da temperatura para as cinco amostras estudadas. 


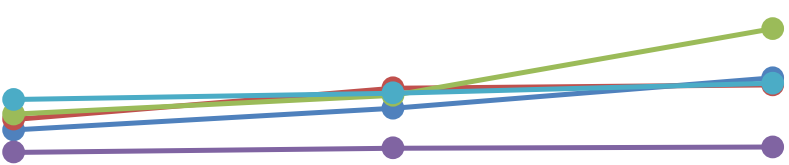

900

1000

1100

Temperatura $\left({ }^{\circ} \mathrm{C}\right)$

Dias D'Ávila

Simões Filho

- Nazaré

- Camaçari

Alagoinhas

Figura 7: Perda ao fogo em função da temperatura para as cinco amostras estudadas.

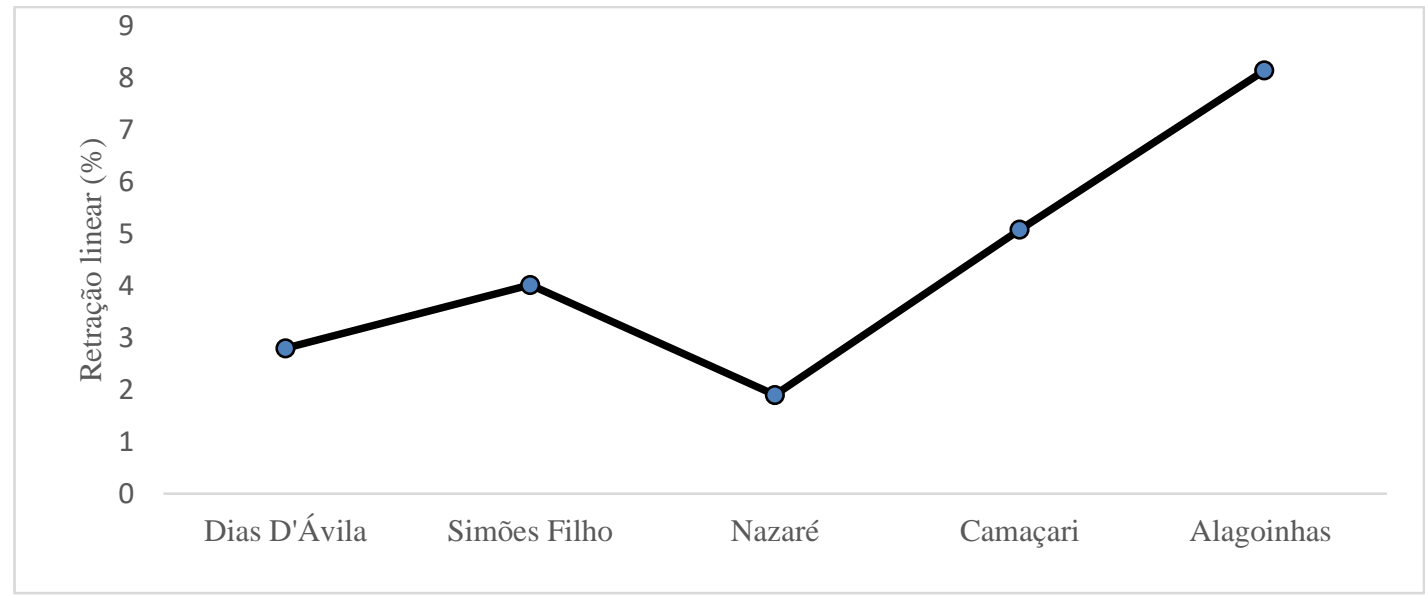

Figura 8: Retração linear de queima das cinco amostras em função da temperatura a $1100{ }^{\circ} \mathrm{C}$.

Tabela 3: Argila comum, tipo várzea, Recôncavo. Composição química porcentual (\%), resistência à flexão, absorção de água, retração linear e perda ao fogo [4].

\begin{tabular}{c|c|c|c|c|c|c|c|c|c|c|c}
\hline MUNICíPIO & $\mathbf{S i O}_{2}$ & $\mathbf{A l}_{2} \mathbf{O}_{3}$ & $\mathbf{F e}_{2} \mathbf{O}_{3}$ & $\mathbf{N a}_{2} \mathbf{O}$ & $\mathbf{K}_{\mathbf{2}} \mathbf{O}$ & $\mathbf{M g O}$ & $\mathbf{C a O}$ & $\mathbf{R F}$ & $\mathbf{A A}$ & $\mathbf{R L}$ & $\mathbf{P F}$ \\
\hline Entre Rios* & 57,03 & 22,73 & 6,64 & 0,05 & 0,43 & 0,22 & 0,12 & 5,00 & 27,00 & 3,00 & 12,81 \\
\hline $\begin{array}{c}\text { Cardial da } \\
\text { Silva }\end{array}$ & 58,52 & 22,07 & 6,27 & 0,25 & 0,87 & 0,71 & 0,17 & 26,63 & 12,94 & 7,87 & 9,92 \\
\hline $\begin{array}{c}\text { Entre Rios/ } \\
\text { Esplanada }\end{array}$ & 58,68 & 21,38 & 6,96 & 0,54 & 0,49 & 0,73 & 0,34 & 21,50 & 12,00 & 6,25 & 9,80 \\
\hline \begin{tabular}{c} 
Entre Rios ** \\
\hline $\begin{array}{c}\text { Inhambupe } \\
\text { Lacustre })\end{array}$
\end{tabular} & 59,78 & 20,02 & 5,36 & 0,47 & 1,42 & 1,05 & 0,31 & 21,50 & 11,00 & 8,25 & 10,15 \\
\hline $\begin{array}{c}\text { Ribeira do } \\
\text { Pombal }\end{array}$ & 60,63 & 19,14 & 5,61 & 2,48 & 0,75 & 1,21 & 0,89 & 26,00 & 12,00 & 7,00 & 8,79 \\
\hline
\end{tabular}

RF - Resistência à Flexão $\left(\mathrm{N} / \mathrm{mm}^{2}\right)$. AA - Absorção de água (\%). RL - Retração linear (\%). PF - Perda ao Fogo (\%).* Capianga; ** Lagoa Redonda 
Tabela 4: Argila comum, tipo formacional, Recôncavo. Composição química porcentual (\%), resistência à flexão, absorção de água, retração linear e perda ao fogo [4].

\begin{tabular}{l|c|c|c|c|c|c|c|c|c|c|c}
\hline MUNICÍPIO & $\mathrm{SiO}_{2}$ & $\mathrm{Al}_{2} \mathrm{O}_{3}$ & $\mathrm{Fe}_{2} \mathrm{O}_{3}$ & $\mathrm{Na}_{2} \mathrm{O}$ & $\mathrm{K}_{2} \mathrm{O}$ & $\mathrm{MgO}$ & $\mathrm{CaO}$ & $\mathrm{RF}$ & $\mathrm{AA}$ & $\mathrm{RL}$ & $\mathrm{PF}$ \\
\hline Itanagra * & 62,30 & 20,88 & 5,71 & 0,06 & 1,11 & 0,61 & 0,03 & 15,0 & 10,00 & 4,0 & 7,55 \\
\hline Itanagra ** & 55,01 & 23,79 & 8,50 & 0,08 & 1,22 & 0,75 & 0,09 & 9,0 & 19,00 & 2,0 & 9,01 \\
\hline Itanagra *** & 56,13 & 23,42 & 7,91 & 0,08 & 1,20 & 0,68 & 0,08 & 18,0 & 13,25 & 4,0 & 9,02 \\
\hline $\begin{array}{l}\text { Alagoinhas } \\
* * * *\end{array}$ & 57,90 & 23,72 & 7,07 & 0,08 & 0,85 & 0,27 & 0,02 & 8,0 & 21,00 & 3,0 & 8,78 \\
\hline $\begin{array}{l}\text { Alagoinhas } \\
* * * * *\end{array}$ & 59,66 & 23,43 & 5,71 & 0,09 & 1,24 & 0,46 & 0,03 & 5,7 & 21,90 & 1,5 & 8,31 \\
\hline
\end{tabular}

RF - Resistência a Flexão (MPa). AA - Absorção d'água (\%). RL - Retração linear (\%). PF - Perda ao Fogo (\%). *Mucugê. ** Estrada da Lagoa I. *** São José do Avena. **** Encantado Norte e ***** Encantado Centro

Tabela 5: Argila fundente, tipo formacional, Recôncavo. Composição química porcentual (\%), resistência à flexão, absorção de água, retração linear e perda ao fogo [4].

\begin{tabular}{c|c|c|c|c|c|c|c|c|c|c|c}
\hline MUNICíPIO & $\mathrm{SiO}_{2}$ & $\mathrm{Al}_{2} \mathrm{O}_{3}$ & $\mathrm{Fe}_{2} \mathrm{O}_{3}$ & $\mathrm{Na}_{2} \mathrm{O}$ & $\mathrm{K}_{2} \mathrm{O}$ & $\mathrm{MgO}$ & $\mathrm{CaO}$ & $\mathrm{RF}$ & $\mathrm{AA}$ & $\mathrm{RL}$ & $\mathrm{PF}$ \\
\hline Alagoinhas & 62,21 & 16,56 & 6,59 & 0,22 & 4,28 & 2,45 & 0,40 & 50,75 & 2 & 8,88 & 5,98 \\
\hline Inhambupe & 61,44 & 16,19 & 7,27 & 0,31 & 4,54 & 2,33 & 0,48 & 57,86 & 2 & 12,00 & 5,70 \\
\hline
\end{tabular}

RF - Resistência a Flexão (N/mm²). AA - Absorção d'água (\%). RL - Retração linear (\%). PF - Perda ao Fogo (\%).

Tabela 6: Argila comum, tipo várzea, Extremo Sul da Bahia. Composição química porcentual (\%), resistência à flexão, absorção de água, retração linear e perda ao fogo [4].

\begin{tabular}{c|c|c|c|c|c|c|c|c|c|c|c}
\hline MUNICÍPIO & $\mathrm{SiO}_{2}$ & $\mathrm{Al}_{2} \mathrm{O}_{3}$ & $\mathrm{Fe}_{2} \mathrm{O}_{3}$ & $\mathrm{Na}_{2} \mathrm{O}$ & $\mathrm{K}_{2} \mathrm{O}$ & $\mathrm{MgO}$ & $\mathrm{CaO}$ & $\mathrm{RF}$ & $\mathrm{AA}$ & $\mathrm{RL}$ & $\mathrm{PF}$ \\
\hline $\begin{array}{c}\text { Teixeira de } \\
\text { Freitas }\end{array}$ & 48,82 & 26,60 & 6,66 & 0,23 & 1,09 & 0,72 & 0,25 & 23,90 & 14,5 & 14,80 & 15,07 \\
\hline Prado & 44,84 & 26,38 & 7,09 & 0,18 & 0,84 & 0,94 & 1,60 & 26,64 & 12,2 & 9,23 & 17,09 \\
\hline
\end{tabular}

RF - Resistência a Flexão (MPa). AA - Absorção d'água (\%). RL - Retração linear (\%). PF - Perda ao Fogo (\%).

Tabela 7: Argila comum, tipo formacional, Extremo Sul Bahia. Composição química porcentual (\%), resistência à flexão, absorção de água, retração linear e perda ao fogo [4].

\begin{tabular}{c|c|c|c|c|c|c|c|c|c|c|c}
\hline MUNICÍPIO & $\mathrm{SiO}_{2}$ & $\mathrm{Al}_{2} \mathrm{O}_{3}$ & $\mathrm{Fe}_{2} \mathrm{O}_{3}$ & $\mathrm{Na}_{2} \mathrm{O}$ & $\mathrm{K}_{2} \mathrm{O}$ & $\mathrm{MgO}$ & $\mathrm{CaO}$ & $\mathrm{RF}$ & $\mathrm{AA}$ & $\mathrm{RL}$ & $\mathrm{PF}$ \\
\hline Mascote & 62,87 & 18,67 & 6,82 & 0,22 & 3,19 & 1,22 & 0,29 & 11,50 & 17,50 & 3,5 & 6,50 \\
\hline Camacã & 64,59 & 19,23 & 5,13 & 0,14 & 0,89 & 0,52 & 0,31 & 18,00 & 16,00 & 2,5 & 7,58 \\
\hline $\begin{array}{c}\text { Mascote } \\
\text { (Estica) }\end{array}$ & 60,80 & 19,58 & 12,50 & 1,10 & 4,20 & 1,30 & 0,12 & 20,44 & 13,44 & 3,0 & 7,11 \\
\hline
\end{tabular}

RF - Resistência a Flexão (MPa). AA - Absorção d'água (\%). RL - Retração linear (\%). PF - Perda ao Fogo (\%).

\section{DISCUSSÃO}

Para a produção de blocos cerâmicos é indicado valores superiores a 5,0 Mpa para tensão de ruptura na flexão. Contudo, outros fatores do processo podem ser otimizados, assim como alguma mistura de matériasprimas. Na Figura 6, nota-se que a absorção de água é sempre inversamente proporcional a resistência à flexão, com maior valor para a amostra de Simões Filho e a menor obtida pela amostra de Alagoinhas, que apresenta maior teor de $\mathrm{Al}_{2} \mathrm{O}_{3}(18,64 \%)$ e valor relativamente alto de $\mathrm{K}_{2} \mathrm{O}$ e menor absorção de água. $\mathrm{O}$ mesmo segue para as de Nazaré e Dias D'Ávila.

Segundo SOUZA SANTOS [20], as faixas de variação da água de plasticidade dos grupos de argilominerais são: a) Caulinita de 8,9 a 56,3\%; b) Ilita de 17,0 a 38,5\%; e c) Montmorilonita de 82,9 a 
250,0\%. Segundo dados da literatura (BARZAGHI, I. L., 1982, SALGE, A., 1982), os valores das absorções de água das características cerâmicas das argilas utilizadas para cerâmica estrutural após secagem $\left(110^{\circ} \mathrm{C}\right) \mathrm{e}$ após queima $\left(950^{\circ} \mathrm{C}\right)$ foram : $20,3-22,9-15,1-17,3-17,0$ - 22,6 e 21, (\%) [21].

Com relação aos resultados apresentados na Figura 7 e nas Tabelas de 3 a 7 com os valores indicados na normalização Associação Brasileira de Normas Técnicas, NBR 15270-1. "Componentes Cerâmicos - Parte 1: Blocos cerâmicos para alvenaria de vedação - Terminologia e requisitos", Rio de Janeiro, JJ (2005). (Rec. 20/1 1/2007, Ver. 01/05/2008, Ac. 30/05/2008) [22], que estabelece absorção de água entre 8 e $22 \%$ e resistência mecânica superior a $1,5 \mathrm{MPa}$, verifica-se que todos os corpos de prova desse trabalho atenderam as especificações, com exceção apenas da argila fundente, do Recôncavo Baiano com absorção de água de $2 \%$ (Tabela 6), e da argila comum, tipo várzea do Recôncavo do município de Entre Rios (Capianga) com 27\% (Tabela 3).

Na Figura 7, observa-se a relação direta da perda ao fogo com a resistência à flexão. Logo as maiores correspondem às amostras de Nazaré e Alagoinhas e a menor para a de Camaçari. Analisando as curvas de perda ao fogo, verifica-se que ocorreu uma perda de massa com valores próximos em todas as amostras, variando de 7,0 a $11,5 \%$. No entanto, a amostra Nazaré apresentou uma perda de massa mais acentuada que as demais amostras em todas as temperaturas, o que, provavelmente está associada ao teor de matéria orgânica superior aos das demais amostras. O comportamento de retração de todas as amostras pode ser observado mediante a Figura 8.

Contudo, verifica-se o inverso na Tabela 3, apesar de $12,81 \%$ de perda ao fogo para a amostra do município de Entre Rios, a resistência à flexão correspondeu a $5 \mathrm{MPa}$, uma absorção de água de $27 \%$, com poucos elementos alcalinos. Valores equivalentes foram obtidos para o município de Inhambupe (Lacustre) com resistência à flexão de 5,6 MPa com absorção de água um pouco menor de $17 \%$. Ainda na Tabela 3 , encontra-se valores equivalentes entre os Municípios de Cardial da Silva e Ribeira do Pombal com resistência à flexão de 26,6 e 26\% MPa e absorção de água de 12,9 e 12\%, respectivamente. Os municípios de Entre Rios/ Esplanada e Lagoa Redonda com 21,5 MPa, absorção de água de 12 e 11\%, respectivamente, todos com o $\mathrm{Al}_{2} \mathrm{O}_{3}$ entre 19,14 e $22,73 \%$.

A distribuição granulométrica com maior teor de finos, produz um efeito sinterizante mais eficiente, uma vez que as reações têm início na superfície dos grãos. A argila sendo mais dura e com maior teor de quartzo e feldspato, por exemplo, resultou com uma granulometria de moagem mais grossa retardando o início da difusão sólida e a formação de suficiente fase fluída para "molhar" os grãos e apresentar aumento progressivo das reações de sinterização via fase líquida. Para misturas preparadas tendo como base as propriedades das argilas individuais, vai depender da taxa de densificação, que por sua vez depende do empacotamento adquirido na mistura e do teor de fundentes na mesma [23]. Os fundentes atuam na formação dessa fase líquida, porque também preenchem os vazios nas estruturas dos materiais, contribuindo para aumentar a densidade e reduzir a porosidade por meio de um processo chamado comumente de vitrificação (Figura 2, $2^{\mathrm{a}}$ queima).

Os fundentes mais utilizados nas cerâmicas, sobretudo para construção civil, são as matérias-primas ricas em $\mathrm{Na}_{2} \mathrm{O}$ e $\mathrm{K}_{2} \mathrm{O}$ que vão formar uma fase líquida por fusão própria da sílica, $\mathrm{SiO}_{2}$, e formam eutéticos em pontos de temperaturas de aproximadamente $700{ }^{\circ} \mathrm{C}$ [24]. Observa-se na Tabela 5, as argilas consideradas como fundentes, que o aumento dos óxidos dos metais alcalinos ocorre também com o aumento do $\mathrm{SiO}_{2}$ e da redução do $\mathrm{Al}_{2} \mathrm{O}_{3}$ e da perda ao fogo. Assim, uma argila com grande porcentagem de elementos alcalinos, digamos superior a 7,0\%, são caracterizadas pela alta resistência à flexão $(50,75$ e $57,86 \%)$, baixa absorção de água (2\%), apesar da quantidade insignificante de materiais orgânicos e baixos teores $\mathrm{de} \mathrm{Al}_{2} \mathrm{O}_{3}$, entre 16,19 a $16,56 \%$.

As massas das telhas de elevadas plasticidades apresentam valores de PF compreendidos entre 5 a $7 \%$ Esta PF é atribuída, sobretudo, à eliminação de hidroxilas da caulinita. Uma perda ao fogo excessiva acarreta retração e porosidade durante a queima. [25]. Nas amostras desde trabalho as únicas que as PF estão entre esses valores são as da Tabela 5 das Argila fundente. Esta PF é atribuída, sobretudo, à eliminação de hidroxilas da caulinita, e alguns autores citam como baixos teores de matérias orgânicas nas amostras. Uma perda ao fogo excessiva acarreta retração e porosidade durante a queima.

Nas Tabelas 4 e 6, argilas com valores aproximados de $\mathrm{SiO}_{2}, \mathrm{Al}_{2} \mathrm{O}_{3}$, perda ao fogo e elementos alcalinos, apresentam a mesma tendência quanto a resistência à flexão inversamente proporcional a absorção de água.

Comparando a Tabela 5 com a do município de Mascote (Tabela 7), essa amostra como o elevado teor de elementos alcalinos um pouco inferiores as da Tabela 5, o $\mathrm{Al}_{2} \mathrm{O}_{3}$ elevado para 19,58 \%, a perda ao fogo um pouco superior, $7,11 \%$, reduziu a resistência à flexão para $20,44 \mathrm{MPa}$, e absorção de água foi elevada a $13,44 \%$. 
Analisando todas as curvas da Figura 7, verifica-se que a maior retração ficou com a composição de Argila Forte do Município de Alagoinhas, que representou o material de característica mais plástica igual a $33,2 \%$ e maior resistência a flexão a $1100{ }^{\circ} \mathrm{C}$. Em seguida, os demais municípios de Camaçari, Simões Filho, Dias D'Ávila e Nazaré, também na temperatura de $1100{ }^{\circ} \mathrm{C}$. Nessa temperatura as retrações lineares se apresentaram com um comportamento elevado, ou seja, indicando que a partir dessa temperatura as peças começam a sofrer vitrificação, diminuindo assim a porosidade e promovendo aproximação das partículas. Nas Tabelas de 6 a 7, as maiores retrações lineares também corresponderam às maiores resistências à flexão.

A partir da metade do século passado, com o desenvolvimento tecnológico de novos processos de elaboração e caracterização, materiais cerâmicos inovadores, chamados cerâmicas avançadas ou de engenharia, começaram a serem desenvolvidos, aumentando consideravelmente a área de aplicações desses materiais [26]. Contudo, a EUROPEAN CERAMIC SOCIETY [27] demonstrou que a Cerâmica Tradicional, incluindo a matéria prima das argilas vermelhas aqui estudadas, ainda ocupa um espaço considerável no mundo científico. Geo-polímeros Cimentos, Vidros Esmaltes, Tintas, Material de construção, e Cerâmicas industriais.

\section{CONCLUSÃO}

- O conhecimento detalhado das argilas vermelhas como matéria-prima para indústria cerâmica contribui significativamente para a melhoria das propriedades do produto final, seja para micros ou pequenas empresas, ou para pesquisas com misturas de argilas visando a otimização da qualidade para uma determinada aplicação, ou na introdução de um vasto tipo de resíduos adicionados às argilas vermelhas objetivando soluções sustentáveis mais diretamente no Estado da Bahia;

- A maioria das amostras de argilas possuem altos teores de sílicas (na maioria acima de 58\%) associados a baixos teores de alumina (em média abaixo de $23 \%$ ) que constituem um material genericamente característico para fabricação de cerâmica vermelha;

- Através de pesquisas científicas foi possível verificar uma maior flexibilidade nas aplicações das argilas vermelhas do Estado da Bahia, como nos demais estados para redução de custos de produção e aumento no valor agregado do produto final;

- Os resultados atenderam as especificações da ABNT, NBR 15270-1 que estabelece absorção de água entre 8 e $22 \%$ e resistência mecânica superior a 1,5 MPa, exceto para amostra da argila fundente, do Recôncavo Baiano com absorção de água de $2 \%$ e da argila comum, tipo várzea do Recôncavo do município de Entre Rios (Capianga) com 27\%;

- Para a produção de blocos cerâmicos é indicado valores superiores a 5,0 MPa. Foram obtidos 8,9 MPa para Nazaré e Alagoinhas, 5,3 MPa para Dias d'Ávila, 5,1MPa para Camaçari e 4,8 MPa Simões Filho com menor resistência a ruptura na flexão, menor quantidade de elementos alcalinos e menor porcentagens de $\mathrm{Al}_{2} \mathrm{O}_{3}$ do que a amostra de Camaçari;

- Pelo diagrama de Winkler, apenas as amostras Simões Filho e Alagoinhas (teor de argila plástica compreendido no intervalo de 30 a $38 \%$ - Região B) podem ser indicadas para a produção de telhas. As amostras com o menor teor de argila plástica (intervalo entre 20 a 30\% - Região C), incluem as de Nazaré, Dias d'Ávila e Camaçari, que possuem distribuições granulométricas favoráveis para fabricação de tijolos furados;

- No que diz respeito a plasticidade das argilas obteve-se teores baixos de $\mathrm{SiO}_{2}$ e de metais alcalinos e altos teores de $\mathrm{Al}_{2} \mathrm{O}_{3}$ com alta perda ao fogo, características essas que são consideradas por vários autores por serem argilas de alta plasticidade;

- Os teores de metais alcalinos, óxido silício e de óxido de alumínio juntamente com a perda ao fogo também confirmaram argilas com características de alta resistência à flexão e baixa absorção de água, que tem geralmente uma relação com uma propriedade de excelente plasticidade;

- As argilas também apresentaram perda ao fogo de 5,98\% e 5,70\% referente as argilas fundentes e isso nos remete a inserir uma elevada qualidade para fabricação de massa de telha cujo padrão compreende valores de PF entre 5 a $7 \%$;

Portanto, como considerações finais ressalta-se que cada estudo realizado relacionado as argilas deve ser devidamente caracterizado com e entre as dependências das propriedades físicas, químicas e mecânicas dos materiais, bem como permitir a disponibilização de dados científicos mediante as exigências das normas regulamentadoras para as comercializações específicas. Sendo assim, os resultados evidenciaram a dependência das propriedades com a composição química das argilas de forma sinergética e conciliativa. 


\section{AGRADECIMENTOS}

Os autores agradecem à Paranapanema pelas análises químicas de todas as amostras, e aos técnicos Marinalvo Souza Santos e Emílio Neto pela realização dos ensaios físicos e mecânicos.

\section{BIBLIOGRÁFIA}

[1] DINIS, L.T., et al., "Melhoria da fisiologia e produtividade da videira sob estresse de verão por aplicação foliar de caulim: relações hídricas, fotossíntese e danos oxidativo", https://link.springer.com/article/10.1007/s11099-017-0714-3\#rightslink. Photosynthetica, v. 56, pp. 641 $651,2018$.

[2] $10^{\circ}$ Congresso de Pós-Graduação ANÁLISE ECONÔMICA DO SETOR DE CERÂMICA BRASILEIRO E AS POSSIBILIDADES DE EXPORTAÇÃO Autor(es) CAMILA SANCHES; Orientador(es) MÁRIO PÓLIS. 23 a 25 e outubro de 2012.

[3] SANTOS, F.K., "Indústria de Cerâmica Vermelha e os Índices de Extremos Climáticos para os Estados do Rio Grande do Norte e Paraíba", Dissertação de M. Sc, Universidade Federal do Rio Grande do Norte, Natal, RN, Brasil, 2017.

[4] CBPM. Cerâmica da Bahia, Catálogo de Matérias Primas, $2^{a}$ Edição, 2007. Insumos cerâmicos do recôncavo baiano, $2^{\text {a }}$ Edição 2007.

[5] MACEDO, R.S., MENEZES, R.R., NEVES, G.A., et al. "Estudo de argilas usadas em cerâmica vermelha", Disponível em: https://www.scielo.br/scielo.php?pid=s036669132008000400005\&script=sci_arttext . Cerâmica, v.54, n. 332, pp. 411-417, 2008.

[6] MORAIS, D.M., SPOSTO, R.M., "Propriedades Tecnológicas e Mineralógicas das Argilas e suas Influências na Qualidade de Blocos Cerâmicos de Vedação que Abastecem o Mercado do Distrito Federal". https://www.ceramicaindustrial.org.br/article/5876572c7f8c9d6e028b4709/pdf/ci-11-55876572c7f8c9d6e028b4709.pdf . Cerâmica Industrial, v.11, n. 5/6, pp. 35-38, Set/ Dez. 2006.

[7] SILVA, A.L., et al. “Avaliação de novos depósitos de argilas provenientes da região sul do Amapá visando aplicação na indústria cerâmica". https://www.scielo.br/scielo.php?pid=S036669132018000100069\&script=sci_arttext. Cerâmica, v. 64, n. 369, pp.69-78, Jan./ Mar. 2018.

[8] MME. Ministério de Minas e Energia (2011a). Anuário estatístico: Setor de transformação de não metálicos / Secretaria de Geologia, Mineração e Transformação Mineral. Brasília: SGM, 2017.

[9] CABRAL J.M., MOTTA, J.F., ALMEIDA, A.S., et al. “Argilas para cerâmica vermelha”. In: Rochas \& minerais industriais, cap. 28, pp.583-606, Rio de Janeiro, CETEM/MCT, 2005.

[10] PAIVA FILHO, E.C.C., AGOSTINHO, R.L., JÚNIOR, J.L.T.S., et al., "Cooperação internacional e desenvolvimento tecnológico: controle do processo de queima em fornos Hoffmann para cerâmica vermelha" In: Congresso Brasileiro de Ensino em Engenharia, Brasília, Distrito Federal, Brasil, 14-17 Setembro 2004.

[11] VIEIRA, C.M.F. Estudo da variabilidade das características de uma argila sedimentar. In: Anais do 45o Congresso Brasileiro de Cerâmica, Florianópolis, Brasil, 2001.

[12] RACANELLI, L.A., BRITO, W.S., DILSON, et al. "Caracterização de dois tipos de argilas do município de São Miguel do Guamá utilizados para fabricação de telhas e blocos de vedação. Brazilian Journal of Development Braz. J. of Develop. ISSN 2525-8761 3803. Curitiba, v. 5, n. 4, p. 3803-3812, apr. 2019.

[13] ASSOCIAÇÃO BRASILEIRA DE NORMAS TÉCNICAS. NBR 7181: Solo - Análise granulométrica, Rio de Janeiro, 2016.

[14] LIMITES DE ATTERBERG - ABNT, 2016 - Associação Brasileira de Normas Técnicas, Determinação do Limite de Plasticidade (LP), NBR -7180 e ABNT, 2016, Limite de Liquidez (LL) NBR 6459, Rio de Janeiro, (1984).

[15] ASTM. Standard Test Method for Water Absorption, Bulk Density, Apparent Porosity, and Apparent specific Gravity of Fired White ware Products. ASTM C373-88. ASTM International. 88, n. Reapproved 2006, p. 40-41, 2013.

[16] SANTOS, P.S., Ciência e Tecnologia das Argilas, 3 ed., v.1, São Paulo, Edgard Blücher, 1992.

[17] PRACIDELLI, S., MELCHIADES, F.G.. Importância da Composição Granulométrica de Massas para Cerâmica Vermelha. Disponível em: http://host-article-

assets.s3.amazonaws.com/ci/587656fc7f8c9d6e028b45e7/fulltext.pdf . Cerâmica Industrial, v. 2, n. 01/02, janeiro/abril, 1997. 
[18] VIEIRA, C.M.F., SOARES, T.M., MONTEIRO, S.N. Massas cerâmicas para telhas: características e comportamento de queima. https://www.scielo.br/scielo.php?pid=S0366-

69132003000400009\&script=sci_arttext. Cerâmica 49 (2003) 245-250 245.

[19] ALEXANDRE, A.B.A., "Caracterização dos Blocos Cerâmicos Estruturais Produzidos no Estado do Ceará”, Dissertação de Mestrado apresentada ao programa de Pós-Graduação em Engenharia Civil:

Estruturas e Construção Civil do Departamento de Engenharia Estrutural e Construção Civil da Universidade Federal do Ceará. Aprovada em: 21/12/2017.

[20] SOUZA SANTOS, P. Tecnologia de Argilas. São Paulo: Edgard Blücher, Ed. da Universidade de São Paulo, v. 1, 340 p., 1975.

[21] BARZAGHI, I. L SALGE, A., Argilas para materiais de construção, Cerâmica, v.28, n.151, p.289-93 (1982). Citado em: KOZIEVITCH, V.F.J.; VALENZUELA-DIAZ F.R.; DIAS, J.F. e TOFFOLI, E. S. M.

Caracterização de argilas utilizadas para fabricação de cerâmica estrutural na região de Monte Carmelo, M.G. CONGRESSO BRASILEIRO DE ENGENHARIA E CIÊNCIA DOS MATERIAIS, 14., 2000, São Pedro SP. Anais

[22] Associação Brasileira de Normas Técnicas, NBR 15270-1. “Componentes Cerâmicos - Parte 1: Blocos cerâmicos para alvenaria de vedação - Terminologia e requisitos”, Rio de Janeiro, JJ (2005). (Rec.

20/11/2007, Ver. 01/05/2008, Ac. 30/05/2008).

[23] MORENO, M.M.T., BARTOLOMEU, D., LIMA, R. H. C. Análise do comportamento de queima de argilas e formulações para revestimento cerâmico. Cerâmica v. 55, pp. 286-295, 2009.

[24] EMILIANI, C.P., CORBARA, F. Tecnologia Cerâmica. La Lavorazione, Grupo Editoriale Faenza Editrice, Faenza, v.1, p.97, 1999.

[25] VIEIRA, C. M. F., SOARES, T. M., MONTEIRO, S. N. Cerâmica v. 49, n. 312 , pp. 245-250, 2003.

[26] MATENCIO, T. Importância dos materiais cerâmicos na nossa sociedade. Matéria (Rio J.), v. 25 , n. 1, Epub, Apr 27, 2020.

[27] EUROPEAN CERAMIC SOCIETY (ECerS) - Torino - Italia, In: XVI ECers Conference, [online]. Pp. 16-20 June, 2019.

\section{ORCID}

Tereza Cristina de Farias Guimarães

Arnaud Victor dos Santos

Ariane da Cruz Thedoldi

Danilo Carvalho de Lima https://orcid.org/0000-0002-5125-0056

https://orcid.org/0000-0003-0113-9939

https://orcid.org/0000-0001-7425-7923

https://orcid.org/0000-0001-8479-1628 